\title{
Assesment of Bleeding Risk in Ultrasound-Guided Percutaneous Renal Biopsies
}

\section{Ultrasonografi Eşliğinde Yapılan Perkütan Böbrek Biyopsilerinde Kanama Riskinin Değerlendirilmesi}

\author{
Ömer Faruk Ateş ${ }^{1}$, Erbil Arık ${ }^{1}$, Ogün Taydaş ${ }^{2}$, Ahmed Bilal Genç$^{3}$, Mehmet Halil Öztürk ${ }^{1}$ \\ ${ }^{1}$ Sakarya Universitesi Tıp Fakültesi Radyoloji Anabilim Dalı \\ ${ }^{2}$ Sağlık Bilimleri Üniversitesi İstanbul Haydarpaşa Numune Eğitim ve Araştırma Hastanesi Aile Hekimliği Kliniği \\ ${ }^{3}$ Sakarya Universitesi Tıp Fakültesi İç Hastalıkları Anabilim Dalı
}

\section{ÖZET}

GiRiŞ ve AMAÇ: Perkütan böbrek biyopsisi renal hastalıkların tanı ve yönetiminde yaygın olarak kullanılan güvenli bir yöntemdir. Çalışmamızın amacı, görüntüleme eşliğindeki perkütan böbrek biyopsilerinde işleme ait kanama riski ile ilişkili faktörleri değerlendirmektir.

YÖNTEM ve GEREÇLER: Mayıs 2018-Aralık 2019 tarihleri arasında girişimsel radyoloji kliniğimize yönlendirilerek ultrasonografi eşliğinde perkütan böbrek biyopsisi yapılan hastalar retrospektif olarak tarandı. Çalışmaya 18 yaş üzeri, işlem öncesi ultrason görüntülemesi ve işlem sonrası patoloji bilgileri mevcut olan hastalar dahil edildi. 18 yaş altı çocuk hastalar ve transplante böbrek biyopsileri çalışma dışı tutuldu.

BULGULAR: Çalışmaya toplam 107 hasta dâhil edildi. Hastaların 57'si erkek (\%53,3), 50'si kadındı (\%46,7). Hastaların yaş ortalaması $47,8 \pm 15,5$ idi. Hastaların işlem öncesi ortalama $\mathrm{Hb}$ değeri 11,2 $\pm 1,7 \mathrm{mg} / \mathrm{dl}$ iken işlem sonrası ortalama $\mathrm{Hb}$ değeri $11,1 \pm 1,7 \mathrm{mg} / \mathrm{dl}$ idi. Hastaların ortanca $\mathrm{Hb}$ düşüşü \%4,2 idi. Yapılan istatistiksel analizde işlem öncesi ile işlem sonrası hemoglobin değerleri arasında anlamlı farklılık saptanmadı $(p=0,864)$. Hemoglobin değerlerindeki düşüş ile hasta yaşı $(p=0,406)$, böbrek boyutu $(p=0,814)$, parankim ekojenitesi $(p=0,175)$ ve parankim kalınlığı $(p=0,254)$ arasında anlamlı korelasyon saptanmadı.

TARTIŞMA ve SONUÇ: Ultrasonografi eşliğinde yapılan böbrek biyopsileri, böbrek hastalıklarının tanısında güvenle kullanılabilecek bir yöntemdir. Her ne kadar kanama riski taşısa da, işlem öncesi uygun değerlendirme ile bu risk en az seviyeye indirilebilir.

Anahtar Kelimeler: böbrek biyopsisi, ultrasonografi, kanama.

\begin{abstract}
INTRODUCTION: Percutaneous kidney biopsy is a safe method widely used in the diagnosis and management of renal diseases. The aim of our study is to evaluate the factors associated with the risk of bleeding associated with the procedure in imaging-guided percutaneous kidney biopsies.

METHODS: Patients who were referred to our interventional radiology clinic between May 2018 and December 2019 and who underwent ultrasound-guided percutaneous kidney biopsy were retrospectively scanned. Patients above 18 years old who had pre-procedure ultrasound imaging and post-procedure pathology information were included in the study. Pediatric patients under 18 years old and transplanted kidney biopsies were excluded.

RESULTS: A total of 107 patients were included in the study. 57 of the patients were male (53.3\%) and 50 were female $(46.7 \%)$. The mean age of the patients was $47.8 \pm 15.5$. The mean $\mathrm{Hb}$ value of the patients before the procedure was $11.2 \pm 1.7 \mathrm{mg} / \mathrm{dl}$, while the mean $\mathrm{Hb}$ value after the procedure was $11.1 \pm 1.7 \mathrm{mg} / \mathrm{dl}$. The median $\mathrm{Hb}$ drop in patients was $4.2 \%$. In statistical analysis, there was no significant difference between hemoglobin values before and after the procedure $(p=0.864)$. No significant correlation was found between the decrease in hemoglobin values and patient age $(p=0.406)$, kidney size $(p=0.814)$, parenchymal echogenicity $(p$ $=0,175)$ and parenchymal thickness $(p=0,254)$.

DISCUSSION AND CONCLUSION: Ultrasound-guided percutaneous kidney biopsy is a method that can be used safely in the diagnosis of kidney diseases. Although there is a risk of bleeding, this risk is minimal with appropriate evaluation before the procedure.

Keywords: renal biopsy, ultrasonography, bleeding, risk factors.
\end{abstract}




\section{Giriş}

Perkütan böbrek biyopsisi renal hastalıkların tanısindave yönetiminde yaygın olarak kullanılan, diğer perkütan biyopsilerde de olduğu gibi güvenli bir yöntemdir (1). Böbrek biyopsileri ilk olarak 1923 yılında açık cerrahi yöntemle uygulanmaya başlanmıştır. Perkütan yöntem ise ilk olarak 1951 y1lında Iversen ve Brun tarafından gerçekleştirilmiş, daha sonra 1953 yllinda Kark ve Muehrck, biyopsi iğnesini yerleştirmeden önce böbreği lokalize etmek amaciyla pron pozisyonda eksploratif iğne kullanımını tanımlamışlardır. İşlemin ultrason görüntüleme rehberliğinde ve otomatik biyopsi iğneleriyle gerçekleştirilmeye başlanmasıyla elde edilen doku yeterliliği ve prosedürün güvenilirliği dramatik olarak artmış, hasta ölüm oran1 $\% 0,12$ 'den $\% 0,02$ 'ye düşmüştür(2,3).

İşlemle ilişkili en sık karşılaşılan komplikasyon kanama olup,geçici hematüri ya da asemptomatik hematomdan yaşamı tehdit eden kanamalara kadar değişkenlik göstermektedir. Renal biyopsi sonrasında meydana gelebilecek kanama komplikasyonları açısından bilinen risk faktörleri yüksek kan basıncı, azalmış renal fonksiyon, obezite, anemi, düşük trombosit sayısı ve hemostaz bozukluklarıdır. İşlemin ultrason eşliğinde yapılmaya başlanması ve otomatik iğnelerin kullanıma girmesiyle birlikte ciddi kanama insidansı azalmıştır (4).

$\mathrm{Bu}$ çalışmadaki amacımız görüntüleme eşliğindeki perkütan böbrek biyopsilerinde işleme ait kanama riski ile ilişkili faktörleri değerlendirerek işlem öncesi hasta değerlendirmesi ve işlem sonrası hasta takibini optimize etmeye katkı sağlamaktır.

\section{Gereç ve Yöntem}

Çalışmada Mayıs 2018-Aralık 2019 tarihleri arasında girişimsel radyoloji kliniğimize yönlendirilerek ultrasonografi eşliğinde perkütan böbrek biyopsisi yapılmışhastalar retrospektif olarak tarandı. Çalışmaya 18 yaş üzeri, işlem öncesi US bilgileri ve işlem sonras1 patoloji bulgularımevcut olan hastalar dahil edildi. 18 yaş altı hastalar, renal kitle biyopsilerive transplante böbrek biyopsileri çalışma dışı tutuldu. Çalışma için etik kurul izni alınd1 (71522473/050.01.04/201).

Çalışma grubu takip amaçlı günübirlik nefroloji servisine yatırılıp işlem için girişimsel radyoloji ünitesinde yönlendirilen hastalardan oluşmaktaydı. Servise yatırılan hastalarda işlem öncesinde kan basıncı ölçümü yapılıp laboratuvar parametreleri için kan örneği alınarakişlem açısından olası bir kontrendikasyon ekarte edilmiştir. Trombosit sayıs 50.000 'in üzerindeve INR'si 1,5 'in altında olan hastalara işlem yapılmıştır. İşlem öncesi hastanın antiagregan ve antikoagülan ilaç kullanımı sorgulanmış ve eğer mevcut ise uygun şekilde kesilmesi veya değiştirilmesi sağlanmıştır.

Hastalar işlemle ilgili bilgilendirilmiş ve hastalardan onam formu alınmıştır. İşlem; hasta sağ lateral dekübit pozisyonda ve bel boşluğuna destekleyici yastık konularak ultrasonografi eşliğinde, uygun cilt dezenfeksiyonu $(\% 10$ povidon iyodin) sağlandıktan sonra, lokal anestezi (\%1 prokain, Priloc, Vem İlaç, Türkiye) uygulanarak, hastaların tamaminda 16 gauge otomatik biyopsi iğnesi (Geotek, Türkiye) kullanılarak yapılmış ve işlemlerin tamamı radyoloji doktorları tarafindan gerçekleştirilmiştir. Biyopsiler teknik olarak engel bir durum yok ise sol böbrekten ve alt polden alınmıştır. Alınan doku örneği, işlemin hemen sonrasında, patolog tarafindan glomerul sayisinın yeterliliği açısından değerlendirilmiş, yeterli glomerul sayısına ulaşılamayan biyopsilerde işlem yeterli glomerul sayısına ulaşmak için birkaç kez tekrarlanmıştır. İşlem sonrasında hastalara nefroloji servisinde 24 saatlik yatak istirahati önerilmiştir. İşlem sonrasında servis takibindelaboratuvar parametreleri olas1 komplikasyonların takibi amacıylayeniden değerlendirilmiştir.

İstatistiksel analiz için MedCalc (ver. 12, Ostend, Belçika) programı kullanıldı. İstatistiksel analiz olarak, tanımlayıcı bulgular kısmında kategorik değişkenler sayı, yüzde ve sürekli değişkenler ise ortalama \pm standart sapma ve ortanca (en küçük, en büyük değer)ile sunuldu. Kolmogorov-Smirnov ve Shaphiro-Wilk testleri ile yapılan normallik değerlendirmesine göre normal dağılıma uygunluğuna göre nonparametrik testler (Mann-Whitney U) ve parametrik testler (student $t$ testi) ile karşılaştırıldı. Korelasyon analizi Pearson korelasyon katsayıs kullanılarak yapıldı. İstatistiksel anlamlılık düzeyi $\mathrm{p}<0,05$ kabul edildi. 


\section{Bulgular}

Çalışmaya toplam 107 hasta dâhil edildi. Hastaların 57'si erkek (\%53,3), 50'si kadındı $(\% 46,7)$. Hastaların yaş ortalaması $47,8 \pm 15,5$ idi. Hastaların işlem öncesi ortalama $\mathrm{Hb}$ değeri $11,2 \pm 1,7 \mathrm{mg} / \mathrm{dl}$ iken işlem sonrası ortalama $\mathrm{Hb}$ değeri $11,1 \pm 1,7 \mathrm{mg} / \mathrm{dl}$ idi. Hastaların ortanca $\mathrm{Hb}$ düşüşü \%4,2 idi. 100 hastada $(\% 93,5) \mathrm{Hb}$ düşüşü \%10'dan az iken yalnızca 7 hastada $(\% 6,5) \% 10$ 'dan fazlaydi. Ancak bu hastaların hiçbirinin takibinde ek işlem gereksinimi veya transfüzyon ihtiyacı olmadi. Hastaların ortalama böbrek boyutu 112,5 $\pm 18,1$ $\mathrm{mm}$ idi. Ortanca parankim ekojenitesi grade 1 olarak saptand. Ortalama parankim kalınlığ 1 $14 \pm 3,5 \mathrm{~mm}$ idi. Patoloji sonucu 18 hastada $(\% 16,8)$ tübülointerstisyel nefrit, 18 hastada $(\% 16,8)$ kronik pyelonefrit, 16 hastada (\%15)IgA nefropatisi, 15 hastada (\%14) membranöz glomerülonefrit, 10 hastada $(\% 9,3)$ diyabetik nefropati, 5 hastada fokal sklerozan glomerüloskleroz $(\% 4,7), 2$ hastada hipertansif nefroskleroz $(\% 1,9), 1$ hastada $(\% 0,9)$ gebelik nefropatisi olarak geldi. 22 hastada $(\% 20,6)$ ise anlamlı boyanma saptanmadı.

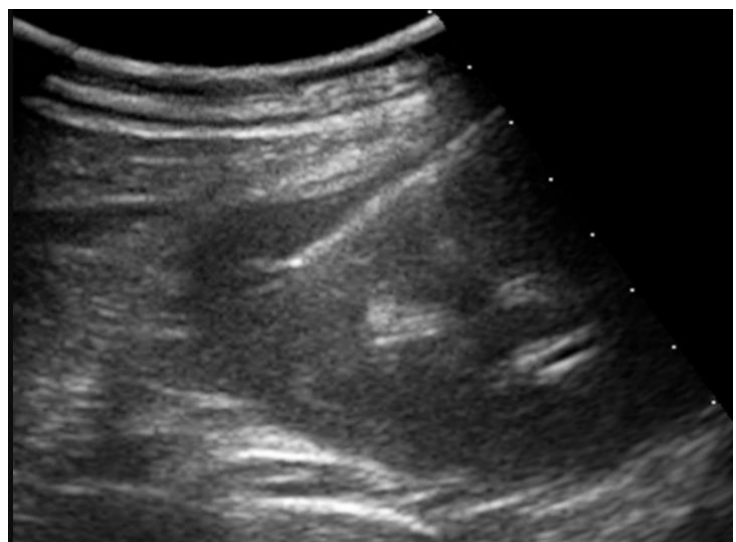

Resim 1: Ultrasonografi eşliğinde böbrek parankim biyopsisi.

Yapılan istatistiksel analizde işlem öncesi ile işlem sonrası $\mathrm{Hb}$ değerleri arasında anlamlı farkl11ı saptanmadı $(\mathrm{p}=0,864)($ Resim 2$) . \mathrm{Hb}$ düşüşü ile hasta yaşı $(\mathrm{p}=0,406)$, böbrek boyutu $(\mathrm{p}=0,814)$, parankim ekojenitesi $(\mathrm{p}=0,175)$ ve parankim kalınlığ $1(\mathrm{p}=0,254)$ arasında anlamlı korelasyonsaptanmad.

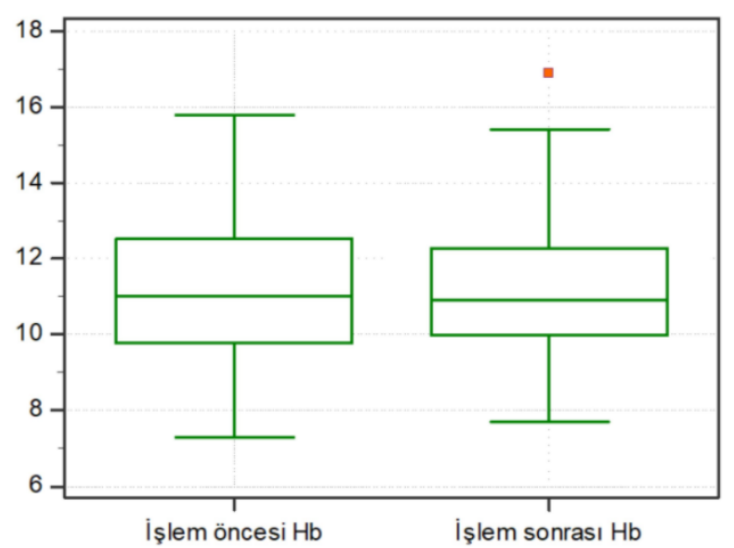

Resim 2: İşlem öncesi ve sonrası $\mathrm{Hb}$ değerlerinin karşılaştırılması.

\section{Tartışma}

Çalışmamızın en önemli sonucu işlem öncesi ile sonrası $\mathrm{Hb}$ değerlerinde anlamlı düşüş olmamasıdır. Böbreklerin kardiyak outputun yaklaşık \%20'sini alan yüksek miktarda kanlananorganlar olması ve retroperitoneal lokalizasyonu dolayısıyla etkin kompresyon yapılamaması nedeni ileböbrek biyopsilerindeki majör riskler kanamadır. Kanama komplikasyonları spontan olarakkendini sinırlayan hematüri ve asemptomatik perinefritik hematomdan, hemodinamik instabilite, böbrek kaybı ve ölümle sonuçlanabilen hayatı tehdit edici kanamalara kadar değişkendir $(2,5,6)$. İşlem öncesi ve sonrası protokollerin farklılığı, işlem sonrası gözlem süresinin değişkenliği ve işlemin acil veya elektif şartlarda yapılması kanama riskinin optimal değerlendirmeve yönetiminde tartışmalı sonuçlar doğurmaktadır (7). Ancak yüksek kan basıncı, bozulmuş renal fonksiyon, düşük trombosit sayısı veya trombosit fonksiyon bozukluğu, koagulopati, kadın cinsiyet, yükssek kalibrasyonlu biyopsi iğnesi kullanımı ve altta yatan bazı renal patolojiler (ince bazal membran hastalığ vaskülit, hızlı ilerleyici glomerulonefrit ve akut interstisyelnefrit) kanama komplikasyonu için bilinen risk faktörleridir $(2,8)$. Kanama riski transplante böbreklerde nativ böbreklere oranla daha düşük görülmektedir (7).

CIRSE (Cardivascular and Interventional Radiological Society of Europe) görüntüleme eşliğindeki perkütan girişimsel işlemlerdeki kanama riskini, her bir grup vasküler ve nonvasküler işlemleri kapsayacak şekilde 3 kategoriye ayırmaktadır: düşük riskli (kolay saptanabilen ve kontrol edilebilir kanamalar), 
orta riskli ve yüksek riskli (saptanması veya kontrol edilmesi zor kanamalar). Görüntüleme eşliğinde perkütan böbrek biyopsileri bu rehberde yüksek riskli grupta değerlendirilmektedir. Kılavuz, yüksek kanama riski kategorisindeki işlemlerde işlem öncesi laboratuvar testleri olarak INR, trombosit sayısı ve hematokrit değerinin rutin olarak bakılmasını önermektedir. aPTT değerlendirilmesini ise yalnızca intravenöz (IV) anfraksiyone (klasik) heparin kullanan hastalarda tavsiye etmektedir. $\mathrm{Bu}$ risk kategorisindeki hastalarda kılavuza göre işlem öncesi INR'nin 1,5'in altında olması gerekli olup aPTT normalin 1,5 katı ve üzerinde ise heparinin kesilmesi, trombosit sayis1 ise 50.000'in altında ise transfüzyon yapılmas 1 gerektiği belirtilmektedir. Hematokrit düşüklüğü durumunda transfüzyon için bir eşik değer bulunmamaktadır. Hastalarda asetilsalisilik asit ve klopidogrel işlemden 5 gün önce, fraksiyone (düşük molekül ağırlıklı) heparin ise işlemden 24 saat önce ya da 2 doza kadar kesilmelidir (9).

Nativ böbreklere uygulanan perkütan böbrek biyopsilerinin primer endikasyonları proteinüri, mikroskobik hematüri, sistemik hastalıklarının renal tutulumları ve açıklanamayan böbrek yetmezliklerinin

\section{Referanslar:}

1.Ozturk R, Kemik ve Yumuşak Doku Tümörleri. In: Atay T, ed. Ortopedi ve Spor Yaralanmaları Asistan Kitabı.Ankara; Derman Tibbi Yayınc1lık; 2015:635-704. 2. Bakdash K, Schramm KM, Annam A, Brown M, Kondo K, Lindquist JD. Complications of Percutaneous Renal Biopsy. Semin Interv Radiol. 2019;36(02):097103.

3. Xu D-M, Chen M, Zhou F, Zhao M-H. Risk Factors for Severe Bleeding Complications in Percutaneous Renal Biopsy. Am J Med Sci. 2017;353(3):230-235.

4. Brachemi S, Bollée G. Renal biopsy practice: What is the gold standard? World J Nephrol. 2014;3(4):287-294.

5. Palsson R, Short SAP, Kibbelaar ZA, et al. Bleeding Complications After Percutaneous Native Kidney Biopsy: Results From the Boston Kidney Biopsy Cohort. Kidney Int Rep. 2020;5(4):511-518.

6. Tøndel C, Vikse BE, Bostad L, Svarstad E. Safety and Complications of Percutaneous Kidney Biopsies in 715 Children and 8573 Adults in Norway 1988-2010. Clin J Am Soc Nephrol CJASN. 2012;7(10):1591-1597.

7. Trajceska L, Severova-Andreevska G, DzekovaVidimliski P, et al. Complications and Risks of Percutaneous Renal Biopsy. Open Access Maced J Med Sci. 2019;7(6):992-995. değerlendirilmesidir $(2,10,11)$. PRB genellikle lokal anestezi altında 14-,16- ya da 18-gauge otomatik biyopsi iğneleri kullanılarak gerçekleştirilir. İşlem komplikasyonları majör(kan transfüzyonu, invazif radyolojik ya da cerrahi işlem gereksinimi, şiddetli hipotansiyon, akut renal obstrüksiyon, renal yetmezlik, septisemi veya ölüm) ve minör(şiddetli yan ağrısı, grosshematüri, perinefritik hematom) şeklinde kategorize edilebilir. Avrupa ve Amerika serilerinde tanımlanan minör ve majör komplikasyon oranları sirasıly \%10-20 ve \%1,2-6,6 olarak bulunmuş, İspanya'da yapılan bir çalışmadaki oranlar ise sirasiyla $\% 19,1$ ve $\% 3,7$ olup benzerlik göstermektedir $(12,13)$.

Çalışmamızın bazı kısıtlılıkları vardı. Bunlardan ilki çalışmanın retrospektif ve tek merkezli olması, bir diğeri de hasta sayısının yetersizliği idi. $\mathrm{Bu}$ konuda gelecekte daha geniş kapsamlı, prospektif ve çok merkezli çalışmalar yapılabilir.

Sonuç olarak ultrasonografi eşliğinde yapılan böbrek biyopsileri, böbrek hastalıklarının tanısında güvenle kullanılabilecek bir yöntemdir. Her ne kadar kanama riski taşısa da, işlem öncesi uygun değerlendirme ile bu risk minimal seviyede tutulabilir.

8. Zhu MS, Chen JZ, Xu AP. Factors that can minimize bleeding complications after renal biopsy. Int Urol Nephrol. 2014;46(10):1969-1975.

9. Malloy PC, Grassi CJ, Kundu S, et al. Consensus Guidelines for Periprocedural Management of Coagulation Status and Hemostasis Risk in Percutaneous Image-guided Interventions. J Vasc Interv Radiol. 2009;20(7):240-249.

10. Kawaguchi T, Nagasawsa T, Tsuruya K, et al. A nationwide survey on clinical practice patterns and bleeding complications of percutaneous native kidney biopsy in Japan. Clin Exp Nephrol. 2020;24(5):389-401. 11. Al Turk AA, Estiverne C, Agrawal PR, Michaud JM. Trends and outcomes of the use of percutaneous native kidney biopsy in the United States: 5-year data analysis of the Nationwide Inpatient Sample. Clin Kidney J. 2018;11(3):330-336.

12.Manno C, Strippoli GFM, Arnesano L, et al. Predictors of bleeding complications in percutaneous ultrasound-guided renal biopsy. Kidney Int. 2004;66(4):1570-1577.

13.Pombas B, Rodríguez E, Sánchez J, et al. Risk Factors Associated with Major Complications after UltrasoundGuided Percutaneous Renal Biopsy of Native Kidneys. Kidney Blood Press Res. 2020;45(1):122-130. 